\title{
The impact of computer display height and desk design on muscle activity during information technology work by young adults
}

\author{
L. Straker ${ }^{\mathrm{a}, *}$, C. Pollock ${ }^{\mathrm{b}}$, R. Burgess-Limerick ${ }^{\mathrm{c}}$, R. Skoss ${ }^{\mathrm{a}}$, J. Coleman ${ }^{\mathrm{a}}$ \\ a School of Physiotherapy, Curtin University of Technology, Perth 6845, Australia \\ ${ }^{\mathrm{b}}$ School of Psychology, Curtin University of Technology, Perth 6845, Australia \\ ${ }^{c}$ School of Human Movement Studies, University of Queensland, Brisbane 4072, Australia
}

Received 6 September 2006; received in revised form 9 September 2006; accepted 11 September 2006

\begin{abstract}
Computer display height and desk design are believed to be important workstation features and are included in international standards and guidelines. However, the evidence base for these guidelines is lacking a comparison of neck/shoulder muscle activity during computer and paper tasks and whether forearm support can be provided by desk design. This study measured the spinal and upper limb muscle activity in 36 young adults whilst they worked in different computer display, book and desk conditions. Display height affected spinal muscle activity with paper tasks resulting in greater mean spinal and upper limb muscle activity. A curved desk resulted in increased proximal muscle activity. There was no substantial interaction between display and desk.
\end{abstract}

Crown Copyright $\subset 2007$ Published by Elsevier Ltd. All rights reserved.

Keywords: Computer; Muscle activity; Musculoskeletal disorder; Work-related neck and upper limb disorder

\section{Introduction}

During the late 1980 s, international and national standards and guidelines on computer use were developed in response to the growing reports of musculoskeletal disorders associated with computer use (e.g. AS, 1990; EEC, 1990; ISO, 1997; SCC, 1991). These standards covered workstation tasks (data and word processing, typing, programming, etc.), environment (space, light, noise, heat, etc.), software (usability, dialogues, etc.), hardware (displays, keyboards, non-keyboard input devices, etc.) and workstation (desk, chair, etc.) design in addition to personnel factors (eyesight, physical problems, mental stress, etc.). Many guidelines included information on how the individual should fit the furniture to themselves (e.g. chair height so the knees are $>90^{\circ}$, armrests/keyboard height so elbow angle $>90^{\circ}$ ). Some guidelines provided considerable detail on workstation design such as chair seat height, seat pan

\footnotetext{
* Corresponding author. Tel.: +61 89266 3634; fax: +61 892663699.

E-mail address: L.Straker@curtin.edu.au (L. Straker).
}

depth/width/angle, seat back height/width/length; armrest height/width/length; work surface height, width, depth, leg clearances; keyboard height, placement; and display height/gaze angle, distance, tilt.

These standards and guidelines were based on expert and industry opinion, often using available research evidence. Whilst some standards have been updated more recently (e.g. ANSI, 2002) we believe a serious review of standards is required due to: changes in computing technology, changes in how computers are used, changes in who uses computers, and recent laboratory and field research. Examples of potentially important computer technology changes include: shift from keyboard command to mouse input Graphic User Interface as the norm, increasing replacement of cathode ray tube displays with liquid crystal thin film transistor displays and the development of tablet computers where the user writes on the screen similar to writing on paper and reading from a book. Changes in how computers are used include increasing use for activities of daily living, social communication and entertainment. Changes in who uses computers include 
Table 1

Summary of studies investigating effect of visual display height on muscle activity

\begin{tabular}{|c|c|c|c|}
\hline Reference & Workstation scenario & Visual target & Reported data \\
\hline 1. Aaras et al. (1997) & $\begin{array}{l}n=20 \text { (workers), lab, keyboard, } \\
\text { mouse. Seat height unspecified. Desk } \\
\text { provided forearm support, height } \\
\text { unspecified }\end{array}$ & Unspecified & L/R TRAP, L/R LES \\
\hline $\begin{array}{l}\text { 2. Babski-Reeves et al. } \\
\text { (2005) }\end{array}$ & $\begin{array}{l}n=8 \text { (students), lab, keyboard. Seat } \\
\text { height adjusted for horizontal thigh, } \\
\text { vertical leg; backrest upright. } \\
\text { Keyboard height at sitting elbow } \\
\text { height }\end{array}$ & $\begin{array}{l}17^{\prime \prime} \text { monitor, GA-h at }+15^{\circ},-15^{\circ} \text {. } \\
\text { Tilt } 0-5^{\circ}\end{array}$ & L SPLEN*, L LES $\dagger$ \\
\hline $\begin{array}{l}\text { 3. Bauer and Wittig } \\
\text { (1998) }\end{array}$ & $\begin{array}{l}n=8 \text { (students), lab, keyboard. Seat } \\
\text { height adjusted for horizontal thigh, } \\
\text { vertical leg; backrest upright. Desk } \\
\text { height set } 3 \mathrm{~cm} \text { below elbow height }\end{array}$ & $\begin{array}{l}\text { Monitor unspecified; GA-h at } 0^{\circ},-17.5^{\circ} \text {, } \\
-35^{\circ} \text {; tilt perpendicular; distance } 74,82, \\
105 \mathrm{~cm}\end{array}$ & L CES \\
\hline 4. Karlqvist et al. (1999) & $\begin{array}{l}n=20 \text { (workers), lab, mouse/ } \\
\text { trackball. Seat }(45-75 \mathrm{~cm}) \text { and desk } \\
\text { height }(70-76 \mathrm{~cm}) \text { self selected }\end{array}$ & $\begin{array}{l}\text { Monitor size unspecified; distance to desk } \\
\text { edge } 50 \mathrm{~cm}\end{array}$ & L/R TRAP, R DELT, R EDL \\
\hline 5. Kleine et al. (1999) & $\begin{array}{l}n=9 \text { (workers), lab, keyboard. Seat } \\
\text { height self selected. Desk height } \\
\text { unspecified }\end{array}$ & Unspecified & $\begin{array}{l}\text { L/R CES } \uparrow, \mathrm{L} / \mathrm{R} \text { TES } \uparrow, \mathrm{L} / \mathrm{R} \text { LES } \uparrow, \mathrm{L} / \mathrm{R} \\
\text { TRAP } \uparrow, \mathrm{L} / \mathrm{R} \text { SCM } \uparrow, \mathrm{L} / \mathrm{R} \text { DELT } \uparrow, \mathrm{L} / \mathrm{R} \\
\text { DELT POS }\end{array}$ \\
\hline $\begin{array}{l}\text { 6. Laursen and Jensen } \\
\text { (2000) }\end{array}$ & $\begin{array}{l}n=17 \text { (young/old), lab, mouse. Seat } \\
\text { height unspecified. Desk provided } \\
\text { forearm support, height unspecified }\end{array}$ & $\begin{array}{l}17^{\prime \prime} \text { monitor, distance } 65 \mathrm{~cm} \text {, screen top at } \\
\text { eye height }\end{array}$ & R DELT, L/R TRAP, R CES \\
\hline 7. Saito et al. (1997) & $\begin{array}{l}n=10 \text { (students), lab, keyboard; } \\
\text { chair height adjusted 'appropriately', } \\
\text { desk height } 70 \mathrm{~cm} \text {, keyboard position } \\
4 \mathrm{~cm} \text { from desk edge }\end{array}$ & $\begin{array}{l}\text { Notebook: } 10.4^{\prime \prime} \text { display, desktop: } 14^{\prime \prime} \\
\text { display. Distance self selected }(32.9( \pm 5.4) \text {, } \\
40.6( \pm 4.3) \mathrm{cm})\end{array}$ & 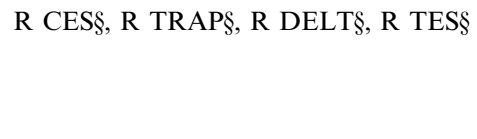 \\
\hline $\begin{array}{l}\text { 8. Sommerich et al. } \\
\text { (2001) }\end{array}$ & $\begin{array}{l}n=16 \text { (eight typists), lab, typing, } \\
\text { mousing, reading. Seat pan set for } \\
\text { thighs horizontal, legs vertical, feet } \\
\text { flat on floor. Keyboard height set at } \\
\text { elbow height, distance for vertical } \\
\text { forearms and elbows at } 90^{\circ}\end{array}$ & $\begin{array}{l}\text { (1) } 14^{\prime \prime} \text { or } 19^{\prime \prime} \text { monitor; }(2) \text { GA-h at } 0^{\circ} \text {, } \\
-17.5^{\circ},-35^{\circ} \text {; tilt perpendicular to GA-h; } \\
\text { distance self-selected }(50-100 \mathrm{~cm})\end{array}$ & $\begin{array}{l}\text { L/R SCM, L/R LEV, L/R TRAP, L/R } \\
\text { CES, L/R TES }\end{array}$ \\
\hline $\begin{array}{l}\text { 9. Sommerich et al. } \\
\text { (2002) }\end{array}$ & $\begin{array}{l}n=10 \text { (unspecified), lab, mouse, } \\
\text { keyboard; chair height adjusted for } \\
90^{\circ} \text { knee flexion with feet flat, } \\
\text { keyboard height at elbow height. } \\
\text { Laptop, with and without external } \\
\text { keyboard and/or mouse }\end{array}$ & $\begin{array}{l}\text { Laptop with screen size unspecified. } \\
\text { Distance and tilt unspecified }\end{array}$ & R TRAP, R PM, R TMI, R DI1 \\
\hline 10. Turville et al. (1998) & $\begin{array}{l}n=12 \text { (unspecified), lab, keyboard, } \\
\text { mouse. Seat height at popliteal height } \\
+2 \mathrm{~cm} \text {, then adjusted for } 90^{\circ} \text { knee } \\
\text { flexion. Keyboard height at elbow } \\
\text { height }\end{array}$ & $\begin{array}{l}\text { Monitor unspecified; GA-h at }-15^{\circ} \text {, } \\
-40^{\circ} \text {; tilt perpendicular; distance } 75- \\
80 \mathrm{~cm}\end{array}$ & $\begin{array}{l}\text { L/R TRAP, L/R CES, L/R TES, L/R } \\
\text { SCM, L/R LEV }\end{array}$ \\
\hline $\begin{array}{l}\text { 11. Straker and Mekhora } \\
(2000)\end{array}$ & $\begin{array}{l}n=20 \text { (students), lab, keyboard. Seat } \\
\text { height at popliteal height, pan } \\
\text { inclined } 5^{\circ} \text { forwards. Desk height at } \\
\text { seated elbow height }\end{array}$ & $\begin{array}{l}\text { Monitor unspecified; GA-h at }-10^{\circ} \text { (tilt } \\
\left.5^{\circ} \text { or }-30^{\circ}\right)\left(\text { tilt } 25^{\circ}\right) \text {; distance self-selected } \\
30-75 \mathrm{~cm}\end{array}$ & L/R TRAP, L/R CES $\|, \mathrm{L} / \mathrm{R}$ TES $\|$ \\
\hline $\begin{array}{l}\text { 12. Villanueva et al. } \\
\text { (1997) }\end{array}$ & $\begin{array}{l}n=10 \text { (unspecified), lab, mouse. Seat } \\
\text { height adjusted so forearm is } \\
\text { horizontal when using mouse } \\
(43.0 \pm 1.8 \mathrm{~cm}) . \text { Desk height } 67 \mathrm{~cm}\end{array}$ & $\begin{array}{l}14^{\prime \prime} \text { monitor; height } 80,100,120 \mathrm{~cm} \text {; } \\
\text { distance unspecified }\end{array}$ & R CES, R TRAP \\
\hline $\begin{array}{l}\text { 13. Villanueva et al. } \\
\text { (1998) }\end{array}$ & $\begin{array}{l}n=10 \text { (unspecified), lab, keyboard; } \\
\text { chair adjusted for horizontal forearm } \\
\text { when hand over home-key, desk } \\
\text { height } 70 \mathrm{~cm}\end{array}$ & $\begin{array}{l}\text { (1) Desktop: } 17^{\prime \prime} \text { monitor; (2) Notebook: } \\
\text { 13. } 8^{\prime \prime} \text { screen; (3) Notebook: } 10.4^{\prime \prime} \text { screen; } \\
\text { (4) Notebook: } 7.2^{\prime \prime} \text { screen; (5) Notebook: } \\
6.1^{\prime \prime} \text { screen. Monitor height: } 96.0,92.9 \text {, } \\
81.1,80.2,76.4 \mathrm{~cm} \text {. Distance, tilt self } \\
\text { selected; distance: } 50.5( \pm 8.7), 49.3( \pm 7.2) \text {, } \\
46.7( \pm 8.0), 43.4( \pm 7.1), 41.2( \pm 6.5) \mathrm{cm} \text {. } \\
\text { Tilt: } 5.5^{\circ}( \pm 3.0), 22.2^{\circ}( \pm 5.7), 32.6^{\circ}( \pm 4.8) \text {, } \\
37.3^{\circ}( \pm 7.1), 41.0^{\circ}( \pm 6.3)\end{array}$ & L CES, L TRAP, L DELT, L ECU \\
\hline
\end{tabular}


Table 1 (continued)

\begin{tabular}{llll}
\hline Reference & Workstation scenario & Visual target & Reported data \\
\hline 14. Visser et al. (2000) & $\begin{array}{l}n=10 \text { (workers), lab, keyboard, } \\
\text { mouse. Seat and desk height } \\
\text { unspecified }\end{array}$ & Unspecified & R TRAP\# \\
\hline
\end{tabular}

Notes:

$\mathrm{L}-$ left

$\mathrm{R}$ - right

DELT - deltoid (assumed anterior)

DELT POS - posterior deltoid

TES - thoracic erector spinae

LES - lumbar erector spinae

SCM - sternocleidomastoid

TRAP - trapezius

CES - cervical erector spinae

LEV - levator scapulae

SPLEN - splenius capitis

EDL - extensor digitorum longus

$\mathrm{PM}$ - pectoralis major

TMI - teres minor/infraspinatus

DI1 - first dorsal interosseus

ECU - extensor carpi ulnaris

EMG normalisation details:

EMG normalised to MVE unless otherwise stated.

*The study normalised to a submaximal reference voluntary contraction (RVE) task of resisting neck flexion while wearing mask with 0.91 kg weight attached, looking straight ahead. A correction factor for RVE to MVE was determined by the ratio between CES data at GA $=-15^{\circ}$ from this study with a mean at the same GA from the literature (Villanueva et al., 1998; Turville et al., 1998; Sommerich et al., 2001).

$\dagger$ Normalised to RVE task of holding $2.27 \mathrm{~kg}$ weight in each hand with arms abducted $90^{\circ}$ in frontal plane and arms parallel to the floor.

$\$$ Normalised to a reference position. A correction factor for RVE to MVE was determined by the ratio between CES data at GA $=00^{\circ}$ from this study with a mean at the same GA from the literature (Villanueva et al., 1998; Laursen and Jensen, 2000; Sommerich et al., 2001).

Normalised to RMS of task.

$\S$ No normalisation. A correction factor was determined by the ratio between CES data at GA $=0^{\circ}$ from this study with a mean at the same GA from the literature (Villanueva et al., 1998; Laursen and Jensen, 2000; Sommerich et al., 2001). The correction factor for TRAP at GA $=0^{\circ}$ used data from Villanueva et al. (1998) and Laursen and Jensen (2000).

INormalised to RVE task of raising head $20 \mathrm{~mm}$ above plinth while prone. Data not converted to relative MVE.

\#Normalised to standard isometric contraction holding $2 \mathrm{~kg}$ load, position unspecified.

the rapid expansion of computer use from specialist computer and data processing occupations to nearly all occupational sectors.

Computer use continues to become more prevalent in both work and home environments. Recent figures from Japan show computers are being used in 93\% of businesses and $47 \%$ of households (Statistics Bureau of Japan, 2005). In 2000, home became the more common site for computer use than work for the first time in Western Australia (33\% vs. $25 \%$ ) (Australian Bureau of Statistics, 2000). Within the adult population, young adults are the most prevalent users. For example, two-thirds of Swedes in the 16-24 years age range use computers daily with $90 \%$ using them at least weekly (Statistics Sweden, 2003).

Given the changes in technology and work practices it is timely to review the research evidence for important current workstation features such as display height and forearm support. In a companion paper (Straker et al., 2008) we have reported new data and reviewed prior evidence for the effect of display height and forearm support on posture. In this paper, we review the evidence for the effect of display height and forearm support on muscle activity.

\subsection{Display height and muscle activity}

We found 14 studies reporting the effect of display height on neck/shoulder surface electromyography (sEMG) for adults. Search strategies included searching Pubmed, Medline and AMed databases using keywords EMG, VDU, computer, display height, and posture, crossing-checking reference lists in relevant articles and searches of authors' library of papers. Table 1 provides a summary of the testing scenario for each of these studies and notes adjustments and estimates we made to provide comparable sEMG data across the studies.

In Figs. 1 and 2, we present a summary of the data from these available studies. It was difficult to synthesise the data from the previous studies due to the different manner that data were both collected and reported. For example, normalisation of sEMG data were to a maximum voluntary exertion (MVE) (eight studies), or to a range of submaximal reference voluntary exertions (RVE) exertions (four studies), or not normalised. Data had to be approximated from figures in five studies. Data were also reported relative to a particular condition (two studies). Where 


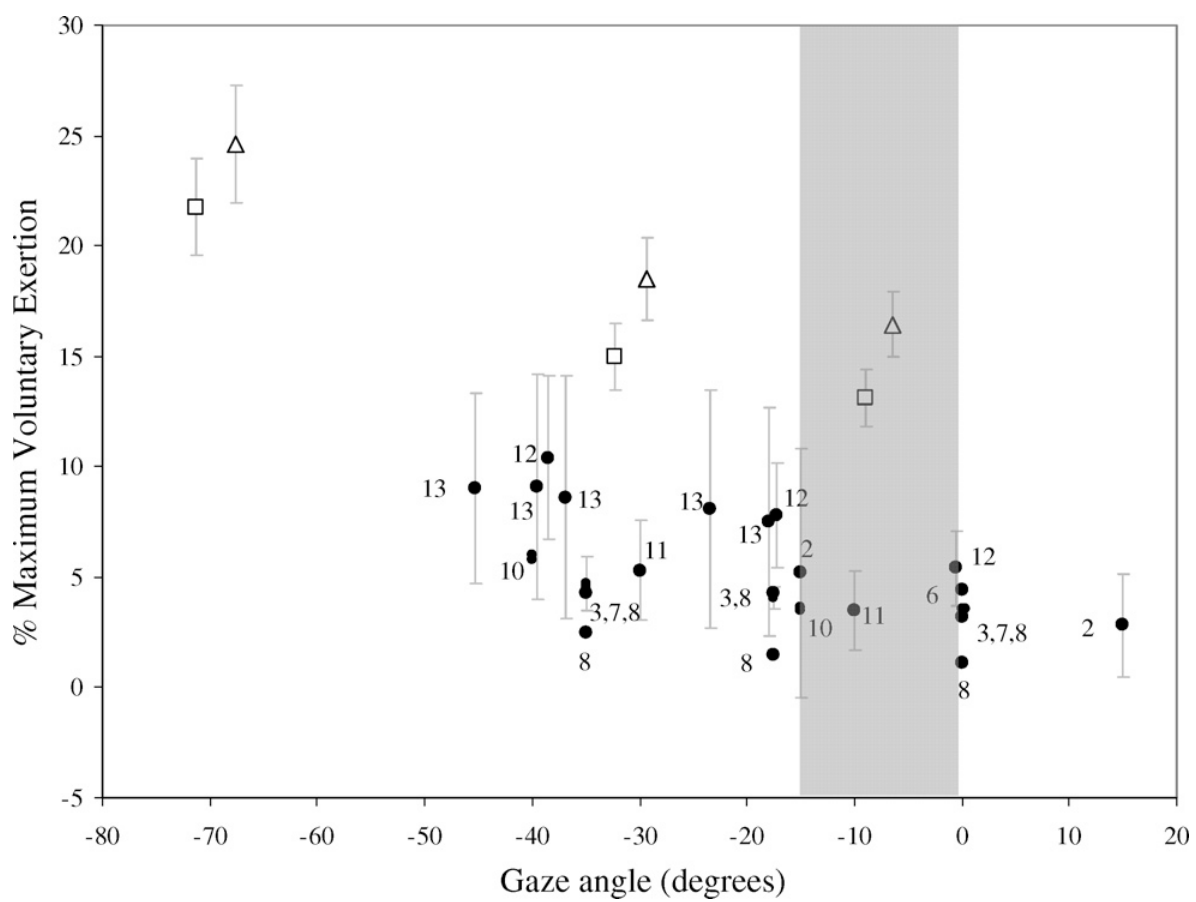

Fig. 1. Cervical erector spinae muscle activity (\% maximum voluntary exertion) relative to gaze angle (eye to display with respect to horizontal) reported in nine studies. (Data from current study shown in open squares (straight desk) and open triangles (curved desk). 'Neutral' zone shown in grey. Numbers correspond to references in Table 1.)

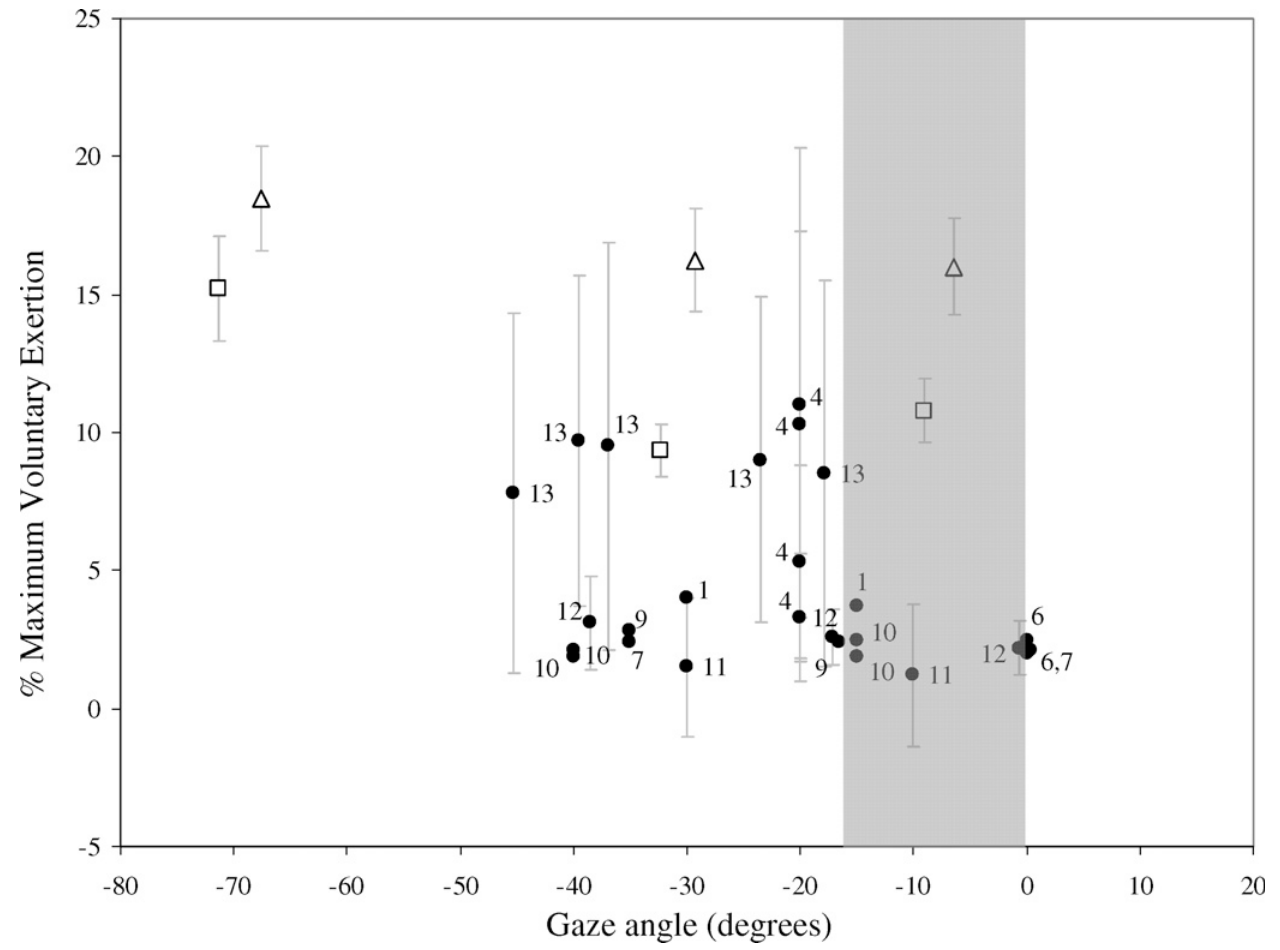

Fig. 2. Upper trapezius muscle activity ( $\%$ maximum voluntary exertion) relative to gaze angle (eye to display with respect to horizontal) reported in eight studies. (Data from current study shown in open squares (straight desk) and open triangles (curved desk). 'Neutral' zone shown in grey. Numbers correspond to references in Table 1.)

possible, the cervical erector spinae and upper trapezius data from papers not reported as \%MVE by gaze angle (Saito et al., 1997; Bauer and Wittig, 1998; Babski-Reeves et al., 2005) were modified using a ratio of the reported RVE to averaged MVE data at a similar gaze angle from other papers (Villanueva et al., 1997, 1998; Turville 
et al., 1998; Laursen and Jensen, 2000; Sommerich et al., 2001) in order to consistently compare relative results across studies.

From Fig. 1, it can be seen that when the visual target is below eye height (negative gaze angles), there is a reasonably consistent relationship with cervical erector spinae (CES semispinalis capitus and splenius capitus) activity increasing with lower gaze angle. There is little data on CES activity for positive gaze angles (ultra-high displays) and large negative gaze angles (very low displays). In contrast, upper trapezius (UT) activity remains fairly constant across moderate gaze angles. Again, however, the available UT data are limited in the low range of display heights, making a comparison with reading from a display on the desk level worthwhile. To aid comparison with postures readers may observe, a 'neutral' zone corre-

Table 2

Summary of studies investigating effect of forearm support on muscle activity

\begin{tabular}{|c|c|c|c|}
\hline Reference & Workstation scenario & Support type & Reported data \\
\hline $\begin{array}{l}\text { Aaras et al. } \\
\text { (1998) }\end{array}$ & $\begin{array}{l}n=20 \text { (workers), lab, keyboard, mouse. Seat height } \\
\text { unspecified. Desk height unspecified }\end{array}$ & Forearm support provided by desk & $\begin{array}{l}\text { L/R TRAP, L/R } \\
\text { LES }\end{array}$ \\
\hline $\begin{array}{l}\text { Bendix and } \\
\text { Jessen } \\
(1986)\end{array}$ & $\begin{array}{l}n=12 \text { (secretaries), lab, typing. Seat height } 52 \mathrm{~cm}(45.5- \\
55.5) . \text { Desk height (interspace bar) } 78.8 \mathrm{~cm}\end{array}$ & $\begin{array}{l}\text { No wrist support provided; wrist support } 1 \mathrm{~cm} \\
\text { below interspace bar, wrist support } 0.5 \mathrm{~cm} \text { above } \\
\text { interspace bar, wrist support and typewriter } \\
\text { elevated } 3 \mathrm{~cm} \text { with support } 0.5 \mathrm{~cm} \text { above interspace } \\
\text { bar }\end{array}$ & $\begin{array}{l}\mathrm{L} / \mathrm{R} \text { TRAP, L/R } \\
\mathrm{WE}\end{array}$ \\
\hline $\begin{array}{l}\text { Cook et al. } \\
\qquad(2004 b)\end{array}$ & $\begin{array}{l}n=15 \text { (workers), lab, keyboard, mouse. Seat height for feet } \\
\text { flat on floor. Desk height so forearms supported with no } \\
\text { shoulder elevation/depression }\end{array}$ & $\begin{array}{l}\text { Forearm support - provided by desk (elbow at } \\
\left.90^{\circ}\right) \text { Wrist support } 20 \mathrm{~mm} \text { high }\end{array}$ & $\begin{array}{l}\mathrm{L} / \mathrm{R} \text { TRAP*}, \mathrm{L} / \mathrm{R} \\
\mathrm{DELT} \dagger\end{array}$ \\
\hline $\begin{array}{l}\text { Erdelyi } \\
\quad \text { et al. } \\
\quad(1988)\end{array}$ & $\begin{array}{l}n=20 \text { (workers, } 12 \text { pain), lab, keyboard. Seat and desk } \\
\text { height set to recommendations by Cakir et al. (1980) }\end{array}$ & $\begin{array}{l}\text { No forearm support with forearms horizontal; } \\
\text { horizontal forearm support, fixated to desk; } \\
\text { horizontal forearm support, fixated to ceiling }\end{array}$ & R TRAPף \\
\hline $\begin{array}{l}\text { Lintula } \\
\text { et al. } \\
\text { (2001) }\end{array}$ & $\begin{array}{l}n=21 \text { (office workers), field (six week intervention), } \\
\text { keyboard, mouse. Seat and desk height unspecified }\end{array}$ & $\begin{array}{l}\text { No support; (1) Ergorest support with mouse pad } \\
\text { for preferred hand; (2) Ergorest supports - with } \\
\text { mouse pad for preferred hand, basic arm support } \\
\text { for non-preferred hand }\end{array}$ & $\begin{array}{l}\text { L/R TRAP. L/R } \\
\text { EDC }\end{array}$ \\
\hline $\begin{array}{l}\text { Moffet et al. } \\
\text { (2002) }\end{array}$ & $\begin{array}{l}n=8 \text { (non-experienced laptop users), lab, keyboard. Seat } \\
\text { height } 46 \mathrm{~cm} \text {, backrest } 100^{\circ} \text {, Desk height } 73 \mathrm{~cm} \text {. Laptop used } \\
\text { on desk or lap }\end{array}$ & $\begin{array}{l}\text { Laptop 1: built in palm rest with keyboard } \\
\text { positioned close to screen; laptop 2: no palm rest } \\
\text { with keyboard positioned close to front of base }\end{array}$ & $\begin{array}{l}\text { R CES } \uparrow, \mathrm{R} \\
\text { TRAPণ, DELT } \uparrow \\
\text { WE }\end{array}$ \\
\hline $\begin{array}{l}\text { Tepper } \\
\text { et al. } \\
(2003)\end{array}$ & $\begin{array}{l}n=38 \text { ( } 19 \text { healthy, } 19 \text { whiplash), lab, keyboard. Seat height } \\
\text { for hip and knee at } 90^{\circ} . \text { Desk height set for eye level at } 10 \mathrm{~cm} \\
\text { below upper border of monitor }\end{array}$ & $\begin{array}{l}\text { Forearm and wrist support provided by 'Up-line' } \\
\text { tilted } 18^{\circ} \text { from horizontal. Forearm support } \\
\text { provided by standard workstation }\end{array}$ & L/R TRAP\# \\
\hline $\begin{array}{l}\text { Visser et al. } \\
\qquad(2000)\end{array}$ & $\begin{array}{l}n=10 \text { (workers), lab, keyboard, mouse. Seat and desk height } \\
\text { unspecified }\end{array}$ & $\begin{array}{l}\text { No support; two arm supports (ERGOarm, } \\
\text { ERGOrest); two wrist supports (TOPtec, TC100/ } \\
210 \text { ) }\end{array}$ & R TRAP \\
\hline
\end{tabular}

Notes:

$\mathrm{L}-$ left

$\mathrm{R}$ - right

DELT - deltoid (assumed anterior)

DELT LAT - lateral deltoid

LES - lumbar erector spinae

TRAP - trapezius

EDC - extensor digitorum communis

ECU - extensor carpi ulnaris

ECR - extensor carpi radialis

WE - wrist extensors

EMG normalisation details:

Note: EMG normalised to MVC unless otherwise stated.

*Normalised to standard isometric contraction holding $1 \mathrm{~kg}$ load, arms held at $90^{\circ}$ abduction in coronal plane, elbows straight, forearm pronated.

$\dagger$ Normalised to standard isometric contraction holding $1 \mathrm{~kg}$ load, arms held at $90^{\circ}$ flexion, elbows straight.

$\$$ Normalised to standard isometric contraction holding $1 \mathrm{~kg}$ load, wrists held in full extension.

No normalisation.

$\S$ Normalised to standard reference posture seated with hip, knee and elbow at $90^{\circ}$ flexion.

$\|$ Normalised to standard reference posture standing with arm in semi-pronated position, performing an isometric contraction against a vertical surface.

\#Normalised to standard isometric contraction while holding arms in position of $90^{\circ}$ abduction.

|Normalised to standard isometric contraction holding $2 \mathrm{~kg}$ load, position unspecified. 
sponding to gaze angles between zero and negative $15^{\circ}$ is shown.

\subsection{Forearm support and muscle activity}

We found 10 studies reported in peer reviewed journals which investigated the effect of forearm support on muscle activity. Table 2 provides a summary of the studies including the workstation details, the type of support provided and the muscle activity variables reported. Aaras et al. (1998) and Visser et al. (2000) report decreased UT activity with the provision of forearm support. However, Cook et al. (2004a,b), Erdelyi et al. (1988) and Tepper et al. (2003) found no difference in UT activity with forearm support. Differences in the nature of the supports and the nat- ure of the tasks performed may have contributed to the differing results. To determine whether a curved desk can provide support, which reduces UT load, further research is required.

\subsection{Interaction effects of display height and forearm support on muscle activity}

Whilst Babski-Reeves et al. (2005) assessed the interaction of display height and chair design, only Aaras et al. (1997) has reported muscle activity data from both display height and forearm support conditions. Although no interaction effects were tested statistically, the figures in their report suggest the reduction in UT activity with
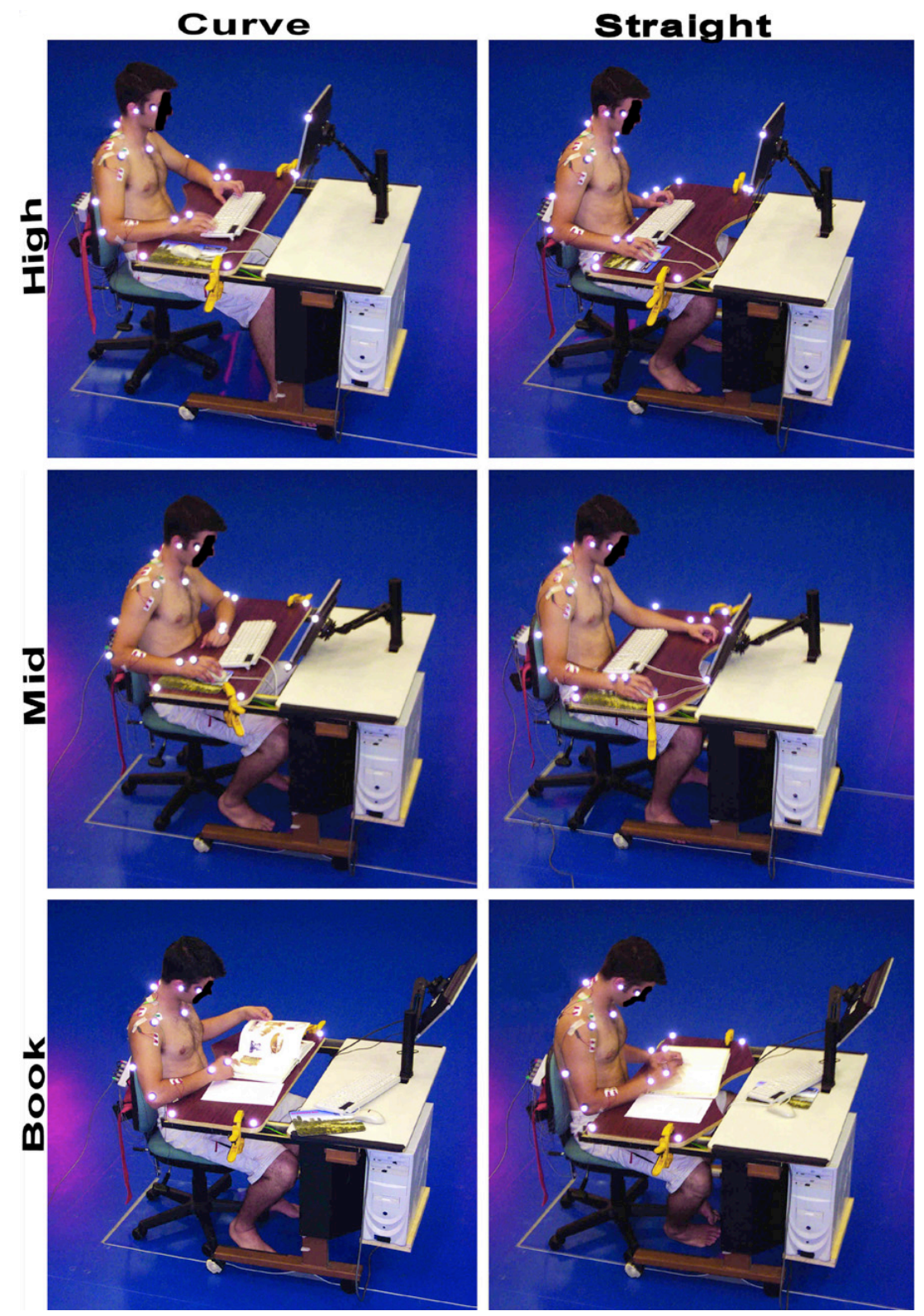

Fig. 3. Photographs of a subject working in the six study conditions - curve and straight desk and high, mid computer displays and book. 
forearm support may be moderated by the display height.

In summary, the available evidence for the effect of display height on upper body muscle activity lacks a comparison with paper based tasks. Similarly, the evidence for the effect of forearm support on muscle activity is inconclusive. Finally, there is no clear evidence on whether display height and desk design features interact. This evidence would help inform workstation design guidelines designed to minimise musculoskeletal disorders associated with information technology tasks. The aim of this study was to assess the independent and interactive effects of display height and forearm support on neck and upper limb muscle activity during work with paper and computer. The results of this study provide complementary evidence to the posture data collected during the study and reported in a companion paper (Straker et al., 2008).

\section{Methods}

\subsection{Study design}

The study used a $2 \times 3$ within subjects design (see Fig. 3 ). The first factor, display, had three levels: (1) high - top of electronic display set at participant's eye height, (2) mid - bottom of electronic display set at desk height, (3) book - paper on desk. The second factor, desk, had two levels: (1) 'traditional' straight desk set at $3 \mathrm{~cm}$ below participant's elbow height with $0^{\circ}$ shoulder flexion and forearms unsupported, and (2) 'horseshoe' partly wrapped around curved desk set at $3 \mathrm{~cm}$ above elbow height enabling full forearm support.

\subsection{Participants}

Thirty-six participants (18 male) were recruited by notices in local universities and community newspapers and personal contacts. Participants had a mean age of 20.6 (SD 2.1) years with no history of significant chronic musculoskeletal disorder in the neck and upper limb, no current neck and/or upper limb pain and no diagnosed rheumatic or acute or chronic musculoskeletal condition. The mean heights of participants were $164.8 \mathrm{~cm}($ SD $5.6 \mathrm{~cm})$ for females and $179.5 \mathrm{~cm}(\mathrm{SD} 6.9 \mathrm{~cm})$ for males. All participants were using computers at least two times per week for a total of at least $2 \mathrm{~h}$ per week, and were right-side dominant for the required tasks.

\subsection{Variables}

sEMG was collected from bilateral CES, bilateral UT, bilateral thoracic erector spinae/scapula retractors (TES), right anterior deltoid (RAD) and right wrist extensor bundle (RWE). The electrode sites (see Table 3) were prepared by shaving, lightly abrading and cleaning with surgical spirits, before pairs of $12 \mathrm{~mm}$ diameter $\mathrm{Ag}-\mathrm{AgCl}$ disposable surface electrodes (Uni-Patch, Wasbasha, MN, USA) were placed $25 \mathrm{~mm}$ centre-to-centre distance. Impedances were checked after electrode attachment and only values of $<5 \mathrm{k} \Omega$ were deemed acceptable.

Participants performed three MVEs in a custom-made dynamometer. The dynamometer consisted of a wooden frame and a detachable leather cuff (Lafayette Instruments Co., Lafayette, IN, USA) or plastic handle attached to a $50 \mathrm{kgf}$ strain gauge (Bongsing Co., Korea) via an inextensible wire cable. The strain gauge and sEMG were connected to a desktop PC via an A/D board (National Instruments, Austin, TX, USA) allowing the participant biofeedback as they elicited each maximal exertion. The tester gave further, verbal encouragement. sEMG and peak strain readings were recorded for the three contractions and an average of the final two contractions used for normalisation.

Raw sEMG signals were collected via an eight channel AMT-8 EMG cable telemetry system (Bortec Biomedical, Alberta, Canada) with analogue differential amplifiers (frequency response: 10$1000 \mathrm{~Hz}$, common mode rejection ratio: $115 \mathrm{~dB}$ ). As most of the sEMG signal power was below $500 \mathrm{~Hz}$, data were sampled at $1000 \mathrm{~Hz}$ for $120 \mathrm{~s}$ in the 2nd and 3rd, 5th and 6th and 9th and 10 th minutes, using customised data acquisition software (LabVIEW, National Instruments, Austin, TX, USA). Data were compared over the different epochs, and as no differences were observed, the mean root mean square (RMS) value over the final 2 min of each trial was normalised to the MVE for each muscle.

Motion data were collected in synchrony with sEMG using a seven camera Peak Motus ${ }^{\circledR}$ 3D Optical Capture System (Peak Performance Technologies Inc., Centennial, CO, USA) via a 32 channel A/D interface (Data Translations 3010, Data Translation Inc., Marlboro, MA, USA). Data acquisition was controlled by the Peak Motus ${ }^{\circledR} 8$ (Peak Performance Technologies Inc., Centennial, CO, USA) software. The method for acquiring kinematic data have been reported in a companion paper (Straker et al.,

Table 3

Description of electrode placements and MVE protocol used

\begin{tabular}{|c|c|c|}
\hline Electrode placement & Description & MVE protocol \\
\hline $\begin{array}{l}\text { Right and left cervical } \\
\text { erector spinae }\end{array}$ & $\begin{array}{l}\text { The midpoint between external occipital protruberance and } \\
\text { C7. Electrodes placed lateral to the cervical spinal processes } \\
\text { on the erector spinae muscle bulk }\end{array}$ & $\begin{array}{l}\text { Head extension against a leather cuff placed around the head } \\
\text { over external occipital protruberance and glabella. } \\
\text { Participants were seated }\end{array}$ \\
\hline $\begin{array}{l}\text { Right and left upper } \\
\text { trapezius }\end{array}$ & $\begin{array}{l}\text { Just lateral to the midpoint between } \mathrm{C} 7 \text { spinous process and } \\
\text { acromion }\end{array}$ & $\begin{array}{l}\text { Scapula elevation with straight arms holding a handle. } \\
\text { Participants were standing }\end{array}$ \\
\hline $\begin{array}{l}\text { Right and left thoracic } \\
\text { scapular retractors }\end{array}$ & $\begin{array}{l}\text { Midpoint between } \mathrm{T} 3 \text { and the inferior angle of the scapular. } \\
\text { Electrodes were placed along line between landmarks }\end{array}$ & $\begin{array}{l}\text { Scapula retraction against a handle. Participants supported } \\
\text { contralateral knee and hand on a chair to have trunk } \\
\text { horizontal during vertical pull by scapula }\end{array}$ \\
\hline Right anterior deltoid & $\begin{array}{l}\text { The midpoint of the fibres of anterior deltoid between the } \\
\text { anterior acromion and deltoid insertion }\end{array}$ & $\begin{array}{l}\text { Upper arm flexion against a leather cuff around the distal arm. } \\
\text { Participants were seated with the elbow flexed at } 90^{\circ} \text {, trying to } \\
\text { punch forward with the arm }\end{array}$ \\
\hline Right wrist extensors & $\begin{array}{l}1 / 3 \text { distance between the right lateral humeral epicondyle and } \\
\text { radial styloid process. Active wrist extension was encouraged } \\
\text { to palpate the muscle bulk before placement }\end{array}$ & $\begin{array}{l}\text { Wrist extension vertically holding handle. Participants were } \\
\text { seated with forearm supported on a height adjustable table }\end{array}$ \\
\hline Common ground & Mid clavicle & N/A \\
\hline
\end{tabular}


2008). For the purposes of this study, gaze angle was calculated from the midpoint between markers at the bilateral outer canthi, and the centre of the display, and is reported relative to the sagittal plane with respect to horizontal.

Variability of movement and muscle activity, as well as performance and the psychological experience of flow (Arrowsmith and Pollock, 2001; Webster et al., 1993), were also measured and will be reported separately.

\subsection{Procedure}

The study was conducted in a climate and lighting controlled motion analysis laboratory. A standard office chair (Burgtec, Perth Western Australia) was adjusted to the participant's popliteal height. A specially designed desk was adjusted to height and shape (straight/horseshoe). An adjustable height display arm (Swing Arm Single, Atdec Pty Ltd. Padstow, New South Wales) was used to adjust the $15^{\prime \prime}$ LCD display (model LM520, AOC, Fremont, CA, USA) so the top of the display was set level at participant eye height, bottom of display at desk height, or turned away from the participant during paper conditions. The same keyboard (model KM-2601, TurboStar, China) and mouse (Optical Wheel Mouse, Microsoft, Redmond, WA, USA) were used in all computer conditions. Six equivalent general knowledge reading and activity sheets were developed and for each participant the six topics were randomly assigned to the six conditions.

Following electrode placement, participants performed MVEs for each muscle using the specially designed rig. Participants then moved to the study workstation and performed the interactive task involving reading and writing on paper or reading from computer display and keyboard and mouse data entry for $10 \mathrm{~min}$. After each task participants moved away from the desk area and reported discomfort and flow. After a 5 min break the participant returned to the now modified workstation and worked in the next condition for $10 \mathrm{~min}$. The study was approved by the Human Research Ethics Committee of Curtin University.

\section{Results}

Table 4 shows the muscle activities in the different study conditions. Univariate RANOVA with post hoc contrasts were calculated for each dependent variable using a critical alpha level of 0.01 to balance family-wise error and power (Table 5). Huynh-Feldt epsilon corrections were used if Mauchly's test indicated lack of sphericity. Covariate analysis using gender had no effect on the pattern of results and so unadjusted results are given. Significant main effects of display and desk were found on neck and upper limb muscle activities.

Compared with the mid display, the high display resulted in 2\% less right and left CES activity whilst UT activity was the same. There was no difference in scapula retractor, right anterior deltoid or right wrist extensor activity between high and mid displays.

Compared with the mid display, the book display resulted in 5-7\% more CES activity, 3-5\% more UT activity, 2-3\% more TES activity, $1 \%$ more RAD activity and $1 \%$ more RWE activity.

The curved desk resulted in CES muscle activity increasing by $4 \%$ (right) to $2 \%$ (left). Similarly, UT activity was increased whilst using the curved desk by $7 \%$ (right) and $4 \%$ (left). There was no difference in scapula retractor or right anterior deltoid activity and minimal increase in right wrist extensor activity between desks.

Display $\times$ desk interactions were not significant except for a trend for right UT to be less different between display heights with the curved desk.

\section{Discussion}

These data are the first description of adult head and arm muscle activity during computer and paper IT (information technology) use in the same study, enabling comparison without assumptions related to sEMG technique differences. Our study included data input by keying and mouse use in addition to writing with a pen. The study also included reading from an electronic screen (involving

Table 5

Summary of RANOVA results for neck and upper limb muscle activity variables

\begin{tabular}{|c|c|c|c|c|c|c|}
\hline & \multicolumn{2}{|l|}{ Display } & \multicolumn{2}{|l|}{ Desk } & \multicolumn{2}{|c|}{ Display $\times$ desk } \\
\hline & $F_{\mathrm{df}}$ & $p$ & $F_{\mathrm{df}}$ & $p$ & $F_{\mathrm{df}}$ & $p$ \\
\hline Right CES & $33.1_{2,66}$ & $<0.001$ & $34.8_{1,33}$ & $<\mathbf{0 . 0 0 1}$ & $0.2_{2,66}$ & 0.853 \\
\hline Left CES & $41.7_{2,62}$ & $<\mathbf{0 . 0 0 1}$ & $13 \cdot 2_{1,31}$ & 0.001 & $0.3_{2,62}$ & 0.767 \\
\hline Right UT & $2.0_{2,68}$ & 0.143 & $31.3_{1,34}$ & $<0.001$ & $3.1_{2,68}$ & 0.050 \\
\hline Left UT & $13.5_{2,70}$ & $<0.001$ & $13.4_{1,35}$ & 0.001 & $1.3_{2,70}$ & 0.270 \\
\hline Right TES & $21.5_{2,70}$ & $<\mathbf{0 . 0 0 1}$ & $0.0_{1,35}$ & 0.894 & $0.4_{2,70}$ & 0.616 \\
\hline Left TES & $24.8_{2,70}$ & $<0.001$ & $11.2_{1,35}$ & 0.065 & $0.4_{2,70}$ & 0.645 \\
\hline Right AD & $6.5_{2,70}$ & 0.007 & $2.1_{1,35}$ & 0.157 & $0.2_{2,70}$ & 0.804 \\
\hline Right WE & $4.0_{2,70}$ & 0.043 & $4.5_{1,35}$ & 0.042 & $2.2_{2,70}$ & 0.117 \\
\hline
\end{tabular}

Table 4

Mean (standard error) muscle activity (\%MVE) in six display and desk conditions

\begin{tabular}{|c|c|c|c|c|c|c|}
\hline & \multicolumn{2}{|c|}{ High display } & \multicolumn{2}{|l|}{ Mid display } & \multicolumn{2}{|l|}{ Book display } \\
\hline & Curved & Straight & Curved & Straight & Curved & Straight \\
\hline Right CES & $18.1(1.6)$ & $13.4(1.3)$ & $20.1(2.0)$ & $15.4(1.5)$ & $25.4(2.7)$ & $21.4(2.0)$ \\
\hline Left CES & $14.8(1.4)$ & $12.8(1.3)$ & $16.9(1.8)$ & $14.6(1.5)$ & $23.8(2.6)$ & $22.1(2.4)$ \\
\hline Right UT & 18.7 (1.9) & $10.9(1.0)$ & $18.7(1.8)$ & $10.4(1.1)$ & $18.6(1.9)$ & $15.1(1.7)$ \\
\hline Left UT & $13.3(1.6)$ & $10.7(1.3)$ & $13.8(1.9)$ & $8.3(0.8)$ & $18.4(1.9)$ & $15.3(2.1)$ \\
\hline Right TES & $3.8(0.6)$ & $4.0(0.6)$ & $4.2(0.7)$ & $4.0(0.6)$ & $6.0(0.8)$ & $6.1(0.8)$ \\
\hline Left TES & $3.9(0.5)$ & $4.6(0.6)$ & $4.2(0.5)$ & $4.6(0.6)$ & $6.6(0.8)$ & $6.8(0.7)$ \\
\hline Right AD & $2.5(0.3)$ & $2.3(0.3)$ & $2.6(0.3)$ & $2.5(0.3)$ & $3.0(0.4)$ & $2.8(0.3)$ \\
\hline Right WE & $8.0(0.8)$ & $7.6(0.7)$ & $7.7(0.6)$ & $7.5(0.7)$ & $9.9(1.1)$ & $8.3(1.0)$ \\
\hline Gaze angle & $-6.5(0.5)$ & $-9.0(0.4)$ & $-29.3(0.7)$ & $-32.3(0.5)$ & $-67.6(0.9)$ & $-71.3(1.1)$ \\
\hline
\end{tabular}


mouse use for navigation) and from a book (involving page turning). The results therefore apply to the common office work situation involving both computer and paper IT work. In comparison with other display height studies our sEMG data follow the same trend for increasing CES activity with lower gaze angles and no change in UT activity across different gaze angles. Sommerich et al. (2000) also noted the differential effects on CES and UT. The inclusion of working with books/paper on the desk in the current study extends the evidence to lower gaze angles and suggests no change in the relationships seen over mid to high display heights.

However, means in our data are substantially greater than most prior reports. We believe these differences are likely to be due to differences in amplitude normalisation. As indicated in Table 1, some studies conducted no amplitude normalisation (Saito et al., 1997), some normalised to a reference position (Bauer and Wittig, 1998), and some normalised to a submaximal exertion (Babski-Reeves et al., 2005; Kleine et al., 1999; Straker and Mekhora, 2000; Visser et al., 2000). Some studies conducted normalisation procedures in a functional seated position, whilst others used a supine or prone position (Straker and Mekhora, 2000). Of the studies which normalised to MVE some used manual resistance (Karlqvist et al., 1999; Sommerich et al., 2001; Villanueva et al., 1997, 1998) and others a dynamometer (Aaras et al., 1997; Turville et al., 1998).

Given the variation in past procedures we chose a protocol aimed at a high level of consistency. The protocol involved taking the mean of the best two of three trials where each trial consisted of a one second ramp up, 3 s hold of maximum exertion and one second ramp down. The ramped activity was supported with visual feedback to the participant and verbal encouragement and instruction. The mean RMS over the highest one second period was taken as the MVE value for each trial. This protocol, whilst providing good reliability, would provide a lower MVE value than other protocols using a peak rectified sEMG value. The effect of a lower magnitude MVE value is to increase the task amplitudes. Therefore, our higher task amplitudes may be due to the conservative MVE protocol. The consistency in amplitude in prior research is exaggerated in Figs. 1 and 2 as we needed to use group mean data to provide a comparison reference point for all the studies which did not use MVE normalisation. Gathering data from different studies using different protocols (eg inter-electrode distance) is problematic. We would not claim that the amplitudes in Figs. 1 and 2 are accurate. However, we believe the figures are useful in showing relative amplitudes and the overall trends in the available evidence.

In our study, the high display condition resulted in surprisingly small reductions in CES $(-2 \%)$ muscle activity from the mid display condition despite substantial reductions in head $\left(15^{\circ}\right)$ and neck $\left(6^{\circ}\right)$ flexion and gaze angle $\left(23^{\circ}\right)$ (Straker et al., 2008). Fig. 1 shows that prior research has found a similar small reduction. As we have argued, whilst less head flexion has been recommended from simple moment modelling, the load on muscles may be increased with upper cervical extension. Cranio-cervical angle (upper cervical intersegmental angle) increased by $7^{\circ}$ in the high display as a result of a greater reduction in head flexion than in neck flexion. Simple modelling of anti-gravity moment suggests CES activity should be more substantially reduced in the high display condition (e.g. HarmsRingdahl et al., 1986; Snijders et al., 1990; Svensson and Svensson, 2001). In the current study, sEMG has been used to provide estimates of superficial muscle loading, but deep tissue loads are yet to be estimated and these may help explain the failure of simple anti-gravity modelling to account for observed CES sEMG changes. Together with the UT results (no difference to $2 \%$ more with high display) these results suggest a high display probably provides no significant advantage to CES and UT.

The book display resulted in a more substantial effect on CES as predicted by a simple anti-gravity model given the increase in head and neck flexion. However, the increased CES activity may have been due to increased stabilisation requirements associated with the increased head and neck asymmetry observed during book/paper use and/or it may have been due to more movement of the neck (and arms) during use of a book/paper. Other studies (Greig et al., 2005) have found a non-linear increase in CES with moderately marked head/neck flexion when reading from a book. Interestingly, the reduction in CES activity reported at extreme flexion by Harms-Ringdahl et al. (1986) was not observed, suggesting participants were not working at end of range and substantially loading passive connective tissue.

Although left UT was consistently higher during book use than mid display computer use, right was only higher in the straight desk condition. This suggests the increased stabilisation required for handling book/pen was not greater than the increased stabilisation used with greater scapula elevation and shoulder abduction when working with a computer at the curved desk. Bendix and Hagberg (1984) had earlier found median UT activity increased with a desk inclined at $22^{\circ}$ compared with a flat desk when writing, but not with just reading. This complements our data showing the importance of task rather than display height for UT activity.

The book display also resulted in small increases in scapula retractor, right anterior deltoid and right wrist extensor activity. Assuming a higher load represents higher risk would suggest using paper presents a higher risk. However, paper based tasks may also encourage more variation in posture and muscle activity. Therefore, the higher loads observed may have been due to more dynamic and variable muscle loading which could indicate lower risk. Evaluation of muscle activity variation should therefore be conducted.

The curved desk resulted in a moderate increase in CES activity. The curved desk had resulted in a small $\left(2^{\circ}\right)$ decrease in head flexion (Straker et al., 2008), which would usually be expected to be accompanied by a decrease in CES activity as gross flexion moment would be slightly reduced. However, the small decrease in head flexion resulted in an increase in upper cervical extension (as the neck posture was 
unchanged), which may have created an increased CES load. The increase in UT activity with the curved desk was logically associated with an increase in scapula elevation $\left(4-7^{\circ}\right)$ and shoulder abduction $\left(12-17^{\circ}\right)$.

It was anticipated that the increased forearm support provided by the curved desk would result in reduced CES/UT activity as per Aaras et al. (1998). The current results suggest that providing a curved desk does not necessarily provide more support and in fact can lead to increased activity. The desk may have influenced the type of arm support participants chose to use. The previous descriptions of the effect of forearm support and wrist only support have had inconsistent results. Tepper et al. (2003) found a trend for a small increase in UT activity when pain free and neck pain participants worked with elevated full forearm support compared with a floating position. Similarly, Visser et al. (2000) found an increase in UT activity with wrist support, and no real effect of chair arm support. In contrast Cook et al. (2004a) found a reduction in UT and anterior deltoid activity with forearm support provided by a straight desk (as well as with wrist support provided by a wrist rest) compared to a free floating arm position during keying. However, their other study (Cook et al., 2004b) found no differences between free floating and wrist rest conditions for both keying and mouse use tasks. One possible reason for the conflicting results could be the extent to which participants actually used the support provided and the nature of the support they gained (full forearm support or only wrist support). The different desk designs in the current study differentially encouraged different types of support. Regardless of desk type, participants were able to gain full forearm support for $60 \%$ of the time, and some form of support for $82 \%$ of the time (data from post hoc analysis of digital video of participants performing in each condition). Full forearm support was achieved $84 \%$ of the time using the curved desk but only $36 \%$ of the time with the straight desk. However, participants used wrist support for $42 \%$ of the time with the straight desk. The curved desk condition was also novel to participants and the elevated scapula, abducted arm and increased CES and UT activity may have been due to participants not being settled in the new set up. Monitoring posture and muscle activity over a number of weeks would be required to determine if the effect observed in this study was only transient. The randomised and controlled trial in call centres by Rempel et al. (2006) provides the best evidence on the efficacy of forearm support to reduce neck/ shoulder musculoskeletal disorders. They reported a $50 \%$ reduction in diagnosed neck/shoulder incidents over 12 months when using a forearm support, though no change in the risk for right upper limb disorders was found.

As indicated in the companion paper (Straker et al., 2008), there was concern that the curved desk could result in weakening of the scapula retractors due to increased protraction. The lack of difference in sEMG activity together with the very small postural change $\left(2-3^{\circ}\right)$ suggest this concern may not be a problem.
The limitations of this study include those highlighted in the companion posture paper (Straker et al., 2008) - young people, short time periods, typing skill differences, display technology differences and sub-task differences. The limitation of unaccustomed use of a curved desk and the need for longer field trials to determine long term benefit or cost is also acknowledged. Finally, the muscle activity assessed in this paper was only surface EMG and then only some extensor muscles. More information on deeper structure stresses could be usefully gained from biomechanical modelling. As previously indicated this paper only reported mean muscle activity. There is some concern that forearm support may inhibit movement and increase muscle activity monotony so this should be investigated.

\section{Conclusion}

Display and desk design features are critical to the minimisation of musculoskeletal risk as they clearly affect neck and upper limb muscle activities. The study results showed that the expected potential benefits of reduced CES and UT activity associated with less head and neck flexion with a high display were not realised. There was no muscle activity advantage to a high display. The increased head and neck flexion and asymmetry recorded during book use did result in increased CES and UT activity further supporting an increased risk of musculoskeletal disorder when working with paper. The study results also suggest that a higher curved desk resulted in higher CES and UT activity associated with scapula elevation and shoulder abduction. Thus the intended potential benefit of supporting the forearms with a higher curved desk also did not occur. Whilst sEMG assisted in the interpretation of risk related to postural responses to display and desk designs, information on deeper cervical structures and movement variation is needed prior to determining a recommended display position.

\section{Acknowledgements}

We thank the National Health and Medical Research Council of Australia for funding the project (\#229011) and Kevin Netto, Caroline Roper and Lisa Richardson for assistance with data collection and processing.

\section{References}

Aaras A, Fostervold KI, Ro O, Thoresen M, Larsen S. Postural load during VDU work: a comparison between various work postures. Ergonomics 1997;40(11):1255-68.

Aaras A, Horgen G, Bjorset H-H, Ro O, Thoresen M. Musculoskeletal, visual and psychosocial stress in VDU operators before and after multidisciplinary ergonomic interventions. Appl Ergon 1998;29(5): 335-54.

American National Standards Institute. Human factors engineering of computer workstations. Report Number: BSR/HFES100, American National Standards Institute, Washington; 2002.

Arrowsmith M, Pollock C. The occurrence of flow in year six children's use of computers. Perth, Western Australia; 3/12/2001. 
Australian Bureau of Statistics. Use of the internet by householders, Australia. Report Number: 8147.0, Australian Bureau of Statistics, Canberra; 2000.

Australian Standards. Screen-based workstations - Workstation furniture. Report Number: AS 3590.2-1990, Standards Australia Limited, Sydney: Australia; 1990.

Babski-Reeves K, Stanfield J, Hughes L. Assessment of video display workstation set up on risk factors associated with the development of low back and neck discomfort. Int J Ind Ergonom 2005;35:593-604.

Bauer W, Wittig T. Influence of screen and copy holder positions on head posture, muscle activity and user judgment. Appl Ergon 1998;29(3): 185-92.

Bendix T, Hagberg M. Trunk posture and load on the trapezius muscle whilst sitting at sloping desks. Ergonomics 1984;27(8):873-82.

Bendix T, Jessen F. Wrist support during typing - a controlled, electromyographic study. Appl Ergon 1986;17(3):162-8.

Cakir A, Hart DJ, Stewart TFM. Visual display terminals. New York: John Wiley and Sons; 1980.

Cook C, Burgess-Limerick R, Papalia S. The effect of upper extremity support on upper extremity posture and muscle activity during keyboard use. Appl Ergon 2004a;35:285-92.

Cook C, Burgess-Limerick R, Papalia S. The effect of wrist rests and forearm support during keyboard and mouse use. Int J Ind Ergonom 2004b;33:463-72.

Erdelyi A, Sihvonen T, Helin P, Hanninen O. Shoulder strain in keyboard workers and its alleviation by arm supports. Int Arch Occup Environ Health 1988;60:119-24.

European Economic Community. The minimum safety and health requirements for work with display screen equipment. Report Number: 90/270/EEC, The Council of the European Communities; 1990.

Feng Y, Grooten W, Wretenberg P, Arborelius UP. Effects of arm support on shoulder and arm muscle activity during sedentary work. Ergonomics 1997;40(8):834-48.

Greig A, Straker L, Briggs A. Cervical erector spinae and upper trapezius muscle activity in children using different information technologies. Physiotherapy 2005;91:119-26.

Harms-Ringdahl K, Ekholm J, Schuldt K, Nemeth G, Arborelius UP Load moments and myoelectric activity when the cervical spine is held in full flexion and extension. Ergonomics 1986;29:1539-52.

International Standards Organization. Ergonomic requirements for office work with visual display terminals (VDTs). Report Number: ISO 9241-1:1997, International Standards Organization, Geneva: Switzerland; 1997.

Karlqvist L, Bernmark E, Ekenvall L, Hagberg M, Isaksson A, Rosto T. Computer mouse and track-ball operation: similarities and differences in posture, muscular load and perceived exertion. Int J Ind Ergonom 1999;23:157-69.

Kleine BU, Schumann NP, Bradl I, Grieshaber R, Scholle HC. Surface EMG of shoulder and back muscles and posture analysis in secretaries typing at visual display units. Int Arch Occup Environ Health 1999;72(6):387-94.

Laursen B, Jensen BR. Shoulder muscle activity in young and older people during a computer mouse task. Clin Biomech 2000;15(1):S30-3.

Lintula M, Nevala-Puranen N, Louhevaara V. Effects of Ergorest arm supports on muscle strain and wrist positions during the use of the mouse and keyboard in work with visual display units: a work site intervention. Int J Occup Safety Ergon 2001;7(1):103-16.

Moffet H, Hagberg M, Hansson-Risberg E, Karlqvist L. Influence of laptop computer design and working position on physical exposure variables. Clin Biomech 2002;17(5):368-75.

Rempel DM, Krause N, Goldberg R, Benner D, Hurdes M, Goldner GU. A randomised controlled trial evaluating the effects of workstation interventions on upper body pain and incident musculoskeletal disorders among computer operators. Occup Environ Med 2006;63:300-6.

Saito S, Miyao M, Kondo T, Sakakibara H, Toyoshima H. Ergonomic evaluation of working posture of VDT operation using personal computer with flat panel display. Ind Health 1997;35:264-70.
Snijders CJ, van Riel MP, Aghina JC, Stoeckart R. Reading and inclined surfaces. Lancet 1990;335(8692):802.

Sommerich CM, Joines SMB, Hermans V, Moon SD. Use of surface electromyography to estimate neck muscle activity. J Electromyogr Kines 2000;10(6):377-98.

Sommerich CM, Joines SM, Psihogios JP. Effects of computer monitor viewing angle and related factors on strain, performance, and preference outcomes. Hum Factors 2001;43(1):39-55.

Sommerich CM, Starr H, Smith CA, Shivers C. Effects of notebook computer configuration and task on user biomechanics, productivity, and comfort. Int $\mathbf{J}$ Ind Ergonom 2002;30:7-31.

Standards Council of Canada. TBITS 13: A guideline on office ergonomics - implementation criteria. Report Number: Standards Council of Canada, Ottawa: Ontario; 1991.

Statistics Bureau of Japan. Ownership and utilization of equipments and services related to information technology (IT). Available from $<$ http://www.stat.go.jp/english/data/joukyou/2004ni/index.htm> 2005. Last accessed: 26/12/05.

Statistiska Centralbyran (Statistics Sweden). Privatpersoners anvandning av datorer oc internet 2002. Report Number: Statistiska Centralbyran (Statistics Sweden); 2003.

Straker L, Mekhora K. An evaluation of visual display unit placement by electromyography, posture, discomfort and preference. Int $\mathbf{J}$ Ind Ergonom 2000;26(3):389-98.

Straker L, Burgess-Limerick R, Pollock C, Murray K, Netto K, Coleman $\mathrm{J}$, et al. The impact of computer display height and desk design on 3D posture during information technology work by young adults. J Electromyogr Kines 2008;18(2):336-49.

Svensson HF, Svensson OK. The influence of the viewing angle on neckload during work with video display units. J Rehabil Med 2001;33(3):133-6.

Tepper M, Vollenbroek-Hutten MMR, Hermens HJ, Baten CTM. The effect of an ergonomic computer device on muscle activity of the upper trapezius muscle during typing. Appl Ergon 2003;34: $125-30$.

Turville KL, Psihogis JP, Ulmer TR, Mirka GA. The effects of video display terminal height on the operator: a comparison of the $15^{\circ}$ and 40 recommendations. Appl Ergon 1998;29(4):239-46.

Villanueva M, Jonai H, Sotoyama M, Hisanaga N, Takeuchi Y, Saito S. Sitting posture and neck and shoulder muscle activities at different screen height settings of the visual display terminal. Ind Health 1997:35:330-6.

Villanueva MBG, Jonai H, Saito S. Ergonomic aspects of portable personal computers with flat panel displays (PC-FPDs): evaluation of posture, muscle activities, discomfort and performance. Ind Health 1998;36:282-9.

Visser B, de Korte E, van der Kraan I, Kuijer P. The effect of arm and wrist supports on the load of the upper extremity during VDU work. Clin Biomech 2000;15(1):S34-8.

Webster J, Trevino L, Ryan L. The dimensionality and correlates of flow in human-computer interactions. Comput Hum Behav 1993;9: 411-26.

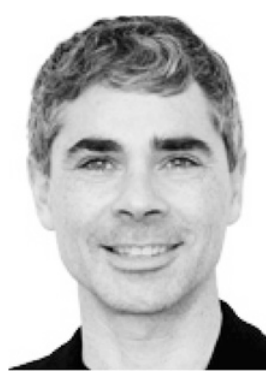

Leon Straker earned a Bachelor of Applied Science in Physiotherapy from the Western Australian Institute of Technology, a Master of Science in Ergonomics from University College London and a Ph.D. in the area of Occupational Medicine from the University of Sydney. He is a Professor in the School of Physiotherapy, Curtin University of Technology and is Director of their research and higher degrees by research programs. Prof. Straker's research interests focus on the prevention of musculoskeletal disorders and include the impact of computer use on children, office ergonomics and participative ergonomics. 


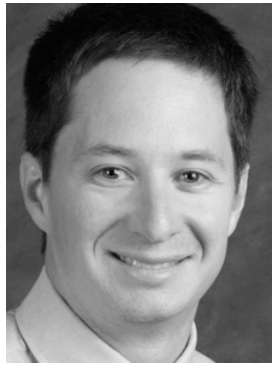

Robin Burgess-Limerick received his Ph.D. from the University of Queensland. He is an Associate Professor in Occupational Biomechanics in the School of Human Movement Studies, The University of Queensland, Australia, where he coordinates postgraduate programs in ergonomics. Dr. Burgess-Limerick's research interests encompass laboratory and field investigations of topics in office ergonomics, participative ergonomics for the prevention of manual tasks related injuries, and reducing injury risks associated with coal mining equipment.

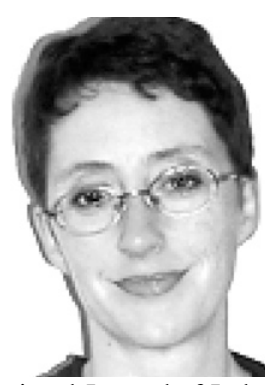

Professor Clare Pollock is the Head of the School of Psychology, Curtin University of technology. She is a graduate of Oxford University (B.A.(Hons) Experimental Psychology) and did her Ph.D. in the Ergonomics Unit, University College London. Since gaining her doctorate she has worked in academia as a teacher and researcher. Her research has focused on the psychological and human factors issues related to safety, complex systems, and technology use. She is a member of Editorial Board for the International Journal of Industrial Ergonomics and was a Member of the Board of the Civil Aviation Safety Authority in her capacity as human factors expert.

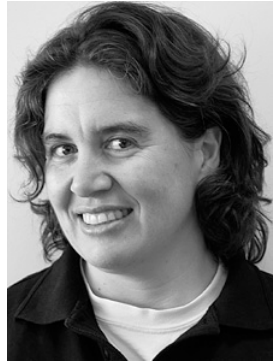

Rachel Skoss is a postdoctoral fellow in the School of Physiotherapy at Curtin University of Technology. She received her Ph.D. in neuromuscular biomechanics from the University of Western Australia. Her research focus is on the coordination of movement, with particular interest in how best to transfer neuromuscular training exercises into habitual muscle activation strategies.

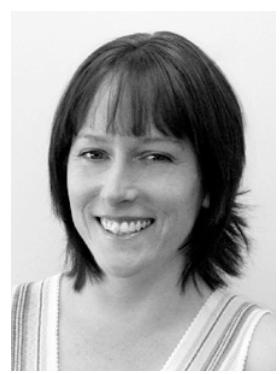

Jemma Coleman holds a Bachelor of Sports Science from Edith Cowan University, Western Australia. She is currently completing in a Masters in Ergonomics at The University of Queensland and works fulltime at Curtin University of Technology in Western Australia. Jemma's research interests include upper quadrant muscle activation with different postures, tasks and rehabilitation regimens. 